\title{
Preoperative Measurement of Submandibular Gland Stone Size
}

\author{
Hyo Seung Jin, Sung Yong Choi, Jae Jin Ko, Ho Jin Son, Hyo Won Lee, \\ Sang Youl Lee, and Jeong Kyu Kim \\ Department of Otolaryngology-Head and Neck Surgery, Catholic University of Daegu School of Medicine, Daegu, Korea
}

\author{
수술 전 악하선 타석의 크기 측정 \\ 진효승 - 최성용 · 고재진 · 손호진 · 이효원 · 이상열 - 김정규 \\ 대구가톨릭대학교 의과대학 이비인후과학교실
}

\author{
Received June 13, 2015 \\ Revised September 1,2015 \\ Accepted September 5, 2015 \\ Address for correspondence \\ Jeong Kyu Kim, MD, PhD \\ Department of Otolaryngology- \\ Head and Neck Surgery, \\ Catholic University of \\ Daegu School of Medicine, \\ 33 Duryugongwon-ro 17-gil, \\ Nam-gu, Daegu 42472, Korea \\ Tel $+82-53-650-4071$ \\ Fax $+82-53-650-4533$ \\ E-mail doctorjkkim@cu.ac.kr
}

Background and Objectives The choice of optimal treatment methods among various gland preserving procedures including transoral surgery, sialendoscopy and extracorporeal lithotripsy for submandibular stones is mainly determined by the size of the stone. We tried to assess the accuracy of ultrasonography (USG) and computerized tomography (CT) for the preoperative estimation of submandibular gland stone size.

Subjects and Method We retrospectively reviewed the medical records of 251 patients who were treated for submandibular stones from January 2008 to December 2014. Eighty patients who checked both preoperative USG and CT were included. Preoperative USG and CT measurements of the submandibular stones were compared to postoperative measurements of removed stones. Effects of stone location and presence of acute infection on preoperative measurements were also assessed. Results The mean submandibular gland stone size was $6.60 \pm 3.8 \mathrm{~mm}$ by USG, $7.23 \pm 4.0 \mathrm{~mm}$ by neck CT and $7.89 \pm 4.7 \mathrm{~mm}$ by the postoperative measurement. USG and CT showed good correlation with the postoperative measurement (correlation coefficient 0.912 and 0.940 , respectively). The location of stone and presence of combined infection showed no significant impact on the accuracy of USG and CT measurement.

Conclusion USG and neck CT showed high accuracy for predicting submandibular gland stone size. However, it should be taken into consideration that the stone size could be greater than that shown by preoperative measurement.

$$
\text { Korean J Otorhinolaryngol-Head Neck Surg 2015;58(12):865-9 }
$$

Key Words Computed tomography $\cdot$ Sialolithiasis $\cdot$ Stone $\cdot$ Submandibular gland Ultrasonography.

\section{서 론}

타석증은 폐쇄성 타액선 질환 중 가장 흔한 원인이며, 주 침샘 중 악하선에서 80 90\% 발병하는 것으로 알려져 있다. ${ }^{1)}$ 타석증은 식후 동통 및 부종을 일으킬 수 있으며, 반복적인 이차 감염을 통하여 타액관 협착 및 타액선 실질 위축을 일으 킬 수 있다. ${ }^{2,3}$

타석증의 전통적인 치료 방법은 타액선 절제술이지만 최근
에는 타액선을 보존하는 최소 침습적인 치료법이 사용되고 있 으며, 침샘 내시경, 충격파 돌깸술, 경구강 타석 제거술 등이 있다. ${ }^{4-6)}$ 타액선을 보존하는 여러 가지 치료 방법 중에 최적의 방법을 선택할 때, 타액선 종류, 타석의 위치, 운동성, 크기, 촉 진 여부 등의 요인들을 고려한다., ${ }^{4,7)}$ 악하선 근위부 타석의 경 우, 타석의 크기가 $5 \mathrm{~mm}$ 이하이면서 타석이 악하선관 내에서 운동성이 좋을 경우 침샘 내시경이 일차적으로 권유되고, 반 면 크기가 $5 \mathrm{~mm}$ 이상이고 고정된 타석의 경우 경구강 타석 
제거술이 일차적으로 권유된다. ${ }^{4)}$ 따라서 악하선 타석의 치료 에서 침샘 내시경 적용 가능성을 판단할 때 타석의 크기를 정 확히 평가하는 것은 매우 중요하다.

타석증의 진단에는 단순 촬영술, 초음파(ultrasonography, $\mathrm{USG}$ ), 전산화단층촬영(CT), 타액선 조영술, 자기공명 타액선 조영술 등이 사용되며, 타석 진단의 민감도와 특이도에 대한 연구가 보고되었다. ${ }^{9-11)}$ 하지만 타석의 실제 크기와 영상의학적 크기 측정을 비교한 연구는 찾기 어렵다. 이에 본 연구에서는 수술 전 초음파와 전산화단층촬영을 이용한 악하선 타석의 크기 측정과 수술 후 제거된 악하선 타석의 실제 크기를 비교
하고자 하였다. 또한 타석의 위치나 급성감염 동반 여부가 초 음파와 전산화단층촬영을 이용한 타석의 크기 측정에 영향을 미치는지 알아보고자 하였다.

\section{대상 및 방법}

본 연구는 2008년 1월부터 2014년 12월까지 악하선 타석증 으로 진단받은 환자 251 명의 의무기록을 후향적으로 분석하 였다. 이 중 1 명은 침샘 내시경을 사용하였고, 나머지 250명은 경구강 타석 제거술을 시행하였으며 악하선 절제술을 시행한
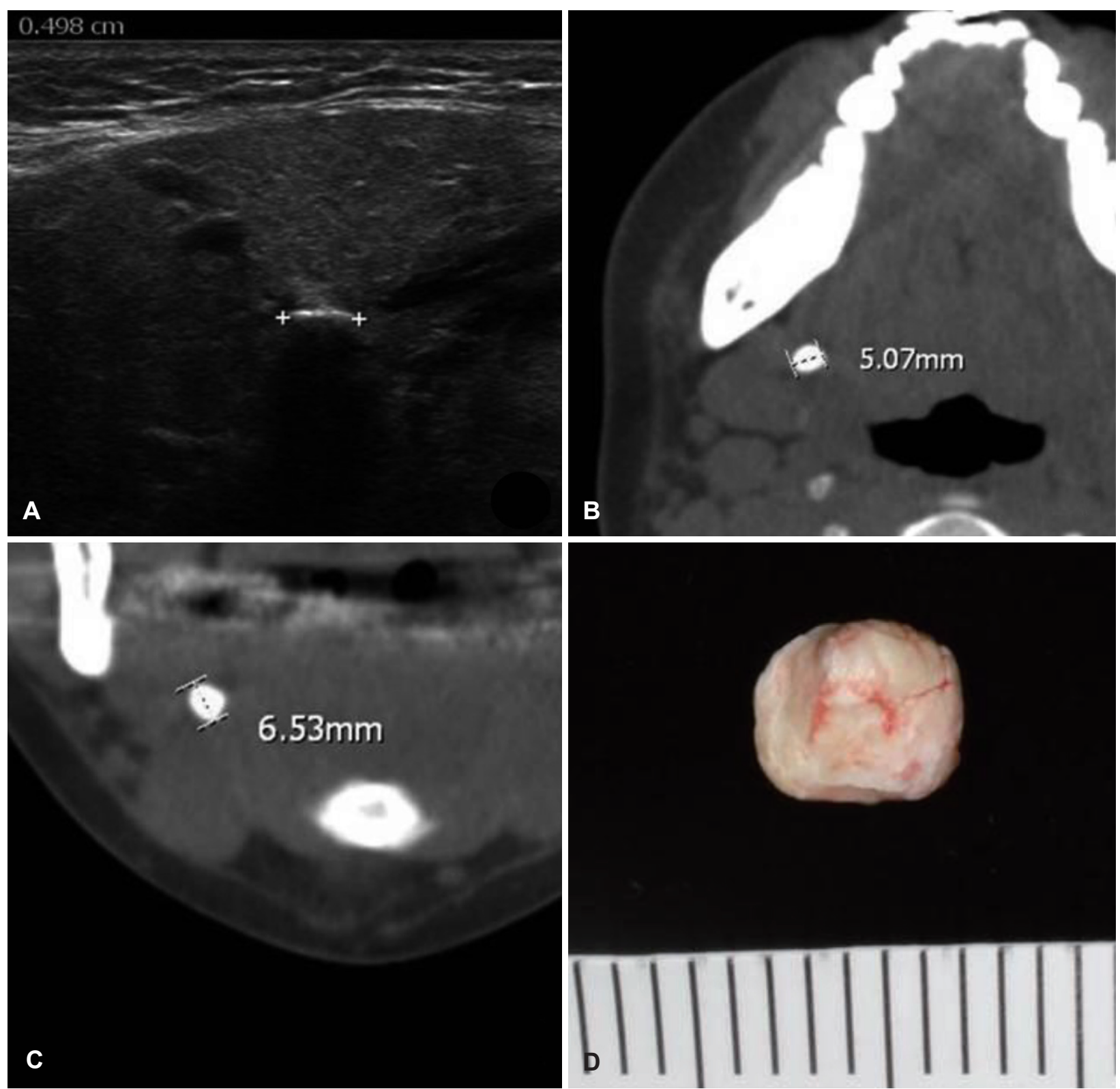

Fig. 1. Measurement of submandibular stone size. Submandibular gland stone size was measured by ultrasonography (USG) (A), axial computed tomography $(\mathrm{CT})(\mathrm{B})$, coronal CT (C), and removed stone (D). Note that removed stone size (7 mm) was larger than USG and CT. 
예는 없었다. 251명 중 수술 전에 전산화단층촬영(CT)과 초음 파(USG)를 모두 시행받은 155명을 대상자로 선정하였다. 여 러 개의 타석을 동반한 경우와 타석 제거 도중 타석이 부서진 경우는 수술 전 영상검사와 제거된 타석의 크기 비교가 곤란 하므로 대상자에서 제외하였고, 의무기록이 불충분한 경우도 대상자에서 제외하였다. 선정기준과 제외기준에 의해 본 연구 에 포함된 대상자는 최종 80명이었다. 타석의 위치는 이학적 소견과 초음파 소견을 기준으로 악하선관 개구부 $1 \mathrm{~cm}$ 이내 에 위치한 경우를 '앞쪽', 턱목뿔근(mylohyoid) 상방에 위치한

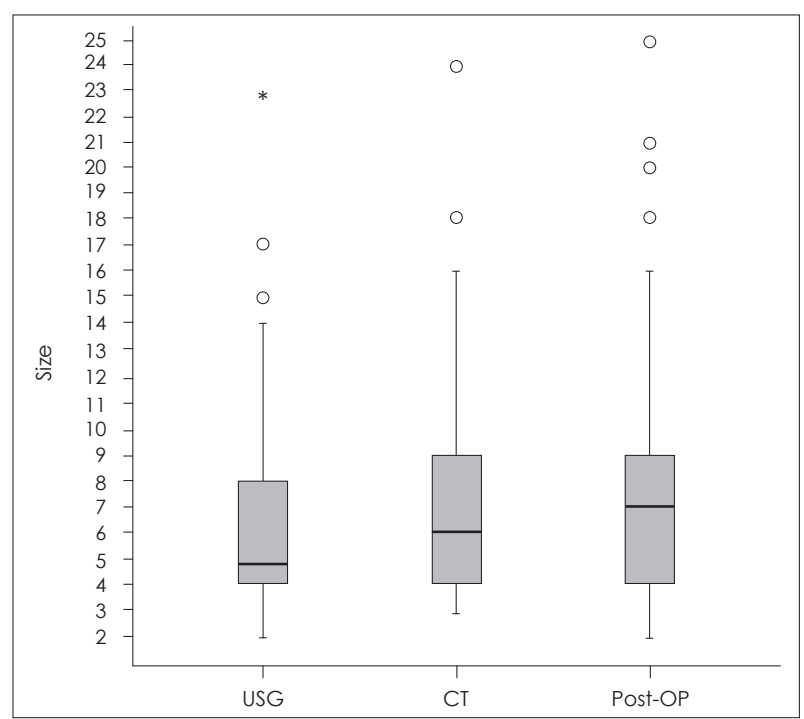

Fig. 2. Submandibular gland stone size measured by USG, CT and removed stone. The box plots denote the interquartile range, the dark line lines indicate medians, and the whiskers represent the highest and lowest values that are not outliers. The open circles represent outliers that are between 1.5 and 3 times the interquartile range, and the asterisks represent extreme outliers that are more than 3 times the interquartile range. USG: ultrasonography, CT: computed tomography, OP: operation.

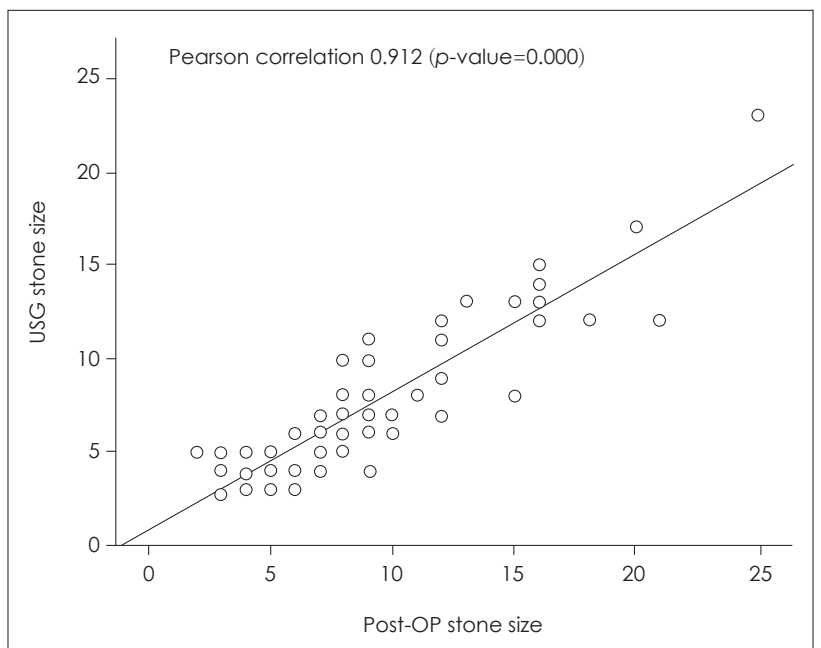

경우를 ‘중간', 턱목뿔근 뒤쪽 경계 후방 또는 하방에 위치한 경우를 '뒤쪽'으로 분류하였으며, 구강저 또는 악하선 부위의 통증, 부종, 발적을 동반하거나 구강저에 농양이 배출되는 경 우에 급성감염이 동반되었다고 판단하였다.

초음파 검사는 수술 전에 한 명의 이비인후과 의사가 시행하 였다. 대상자는 진료실 침대에 앙와위로 누워 어깨받침을 받쳐 경부를 신전하였고, 탐촉자(probe)는 하악골 하연에 평행한 방 향에서 타석을 관찰하였다. 수술 전 초음파 검사 당시 타석의 크기를 측정하여 기록한 자료를 수집하였고, 여러 번 측정된 기록이 있을 경우 큰 값을 수집하였다. 전산화단층촬영상 타 석의 크기는 축면(axial plane)상의 최대 직경을 한 명의 연구자 가 측정하여 수집하였다. 수술 후 제거된 타석의 크기는 수술 직후 한 명의 수술자가 직접 자로 최대 직경과 최소 직경을 측 정하여 기록하였으며, 이 중 최대 직경을 수집하였다(Fig. 1).

수술 전 초음파 및 전산화단층촬영으로 측정된 타석의 크 기는 수술 후 제거된 타석의 크기와 상관분석을 시행하였다. 타석의 위치와 급성감염의 동반 여부가 초음파 및 전산화단 층촬영의 타석 크기 측정에 영향을 미치는지 분석하기 위해 서 수술 전 초음파 및 전산화단층촬영의 측정값과 수술 후 타 석의 측정값의 차이(difference value)를 타석의 위치와 급성 감염 동반 여부에 따라 일원배치분산분석(one-way ANOVA), 또는 두 표본 $\mathrm{t}$ 검정(two sample t-test)을 시행하였다. 통계분 석은 IBM SPSS 19.0(SPSS Inc., Chicago, IL, USA)을 사용 하였으며, 최대 유의수준은 0.05 로 설정하였다.

\section{결 과}

80명 대상자는 남자 37명, 여자 43명이었으며, 평균 나이는

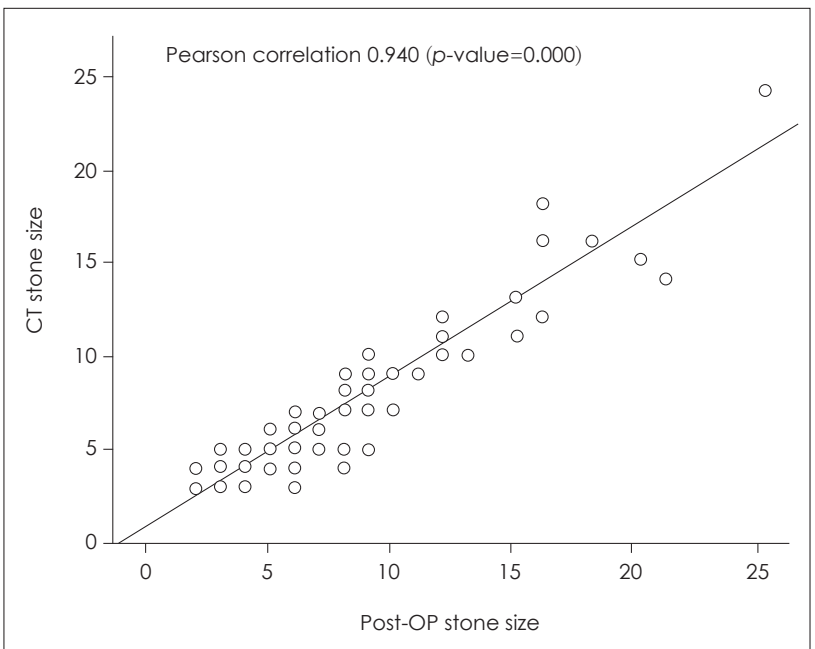

Fig. 3. Correlation between preoperative measurements and postoperative measurements. Correlation coefficient was 0.912 between USG and postoperative measurement and 0.940 between CT and postoperative measurement. USG: ultrasonography, CT: computed tomography, OP: operation. 
35.275세(범위 11 81)였다. 타석은 앞쪽이 9명(11.25\%), 중간이 21 명(26.25\%), 뒤쪽이 50명(62.5\%)이었으며, 급성감염을 동반 한 경우는 62 명 $(77.5 \%)$ 이었다.

악하선 타석 크기의 초음파 측정값은 평균 $6.60 \mathrm{~mm}$ (표준 편차 3.8)였고, 전산화단층촬영 측정값은 평균 $7.23 \mathrm{~mm}$ (표준 편차 4.0)였으며, 수술 후 측정값은 평균 $7.89 \mathrm{~mm}$ (표준편차 4.7)였다(Fig. 2). 악하선 타석 크기의 초음파 측정값과 수술 후 측정값의 상관계수는 $0.912(p$-value $=0.000)$ 였으며, 전산화 단층촬영 측정값과 수술 후 측정값의 상관계수는 $0.940(p-$ value $=0.000)$ 이었다(Fig. 3).

초음파의 수술 전 측정값과 제거된 타석의 측정값의 차이 (difference value)는 앞쪽에서 뒤쪽으로 갈수록 값이 증가하 여 그 정확도가 감소하는 경향을 보였으나 통계적 유의성은 없었다 $(p-v a l u e=0.283)$. 전산화단층촬영의 수술 전 측정값과 제거된 타석의 측정값의 차이도 타석의 위치에 따른 유의한 영향은 없었다 $(p$-value $=0.847)($ Table 1$)$.

초음파의 수술 전 측정값과 제거된 타석의 측정값의 차이 는 급성감염의 동반 여부에 따른 유의한 영향을 보이지 않았 으며 $(p$-value $=0.381)$, 전산화단층촬영의 수술 전 측정값과 제 거된 타석의 측정값의 차이도 급성감염의 동반 여부에 따른 유의한 영향을 보이지 않았다 $(p-v a l u e=0.645)$. 급성감염을 동 반하지 않은 67 명에서는 전산화단층촬영의 차이가 초음파의 차이보다 유의하게 작았고 $(p$-value=0.000), 급성감염을 동반 한 13 명에서는 초음파의 차이가 전산화단층촬영의 차이보다 작았지만 통계적 유의성은 없었다 $(p$-value=0.918)(Table 2).

\section{고 찰}

본 연구는 악하선 타석 크기의 수술 전 영상학적 측정값과
수술 후 제거된 타석의 실제 측정값의 차이를 비교한 최초의 연구이다.

타석의 크기는 침샘 내시경, 충격파 돌깸술, 경구강 타석 제 거술 등 타액선을 보존하는 여러 치료 방법 중에 최적의 치료 법을 선택함에 있어 중요한 역할을 한다., ${ }^{4,8,12-14)}$ 침샘 내시경 은 크기가 작고 침샘관 내에서 움직일 경우 유용하게 사용될 수 있다. 일반적으로 내시경 단독으로 치료 가능한 타석의 크 기는 여러 치료 알고리즘에서 최대 타석의 크기를 3 5 mm로 제한하고 있다. ${ }^{1,4,7,8,15)}$ 충격파 돌깸술은 악하선 타석보다는 이 하선 타석에서 보다 유용하게 사용되며, 타석의 크기가 작을 수록, 또는 $7 \mathrm{~mm}$ 이하의 타석에서 치료 성공률이 높았다고 보고되었다. ${ }^{12,13)}$ 경구강적 제거술의 성공적인 치료에는 타석의 크기 보다는 촉진 여부가 중요하였다. ${ }^{2}$ 하지만 크기가 작거나, 악설골근 아래 깊이 위치하거나, 급성감염과 연부조직 부종을 동반한 타석의 경우 촉진되지 않을 수 있으므로 치료에 어려 움이 있을 수 있다. ${ }^{16)}$ 크기가 큰 악하선 타석을 분석한 다른 연구에서는 $10 \mathrm{~mm}$ 이상의 타석은 이환 기간이 길므로 타액 선 손상 정도가 커서 타석만 제거할 경우 재발이 많을 것으로 가정하였지만, 장기추적을 분석한 결과에서는 타석의 크기가 증상 재발에 유의한 영향이 없었다고 보고하였다. ${ }^{17}$

본 연구에서 악하선 타석 크기의 수술 전 초음파 및 전산화 단층촬영을 이용한 측정값과 수술 후 제거된 타석 크기의 측 정값의 상관계수는 각각 0.912와 0.940을 보였다. 따라서 초음 파 및 전산화단층촬영 두 검사 모두 실제 악하선 타석의 크기 를 정확하게 예측할 수 있는 검사이며, 두 검사를 비교하였을 경우에는 전산화단층촬영이 초음파보다 더 정확한 검사방법 으로 생각할 수 있겠다.

본 연구에서 악하선 타석의 수술 전 초음파 및 전산화단층 촬영의 측정값이 각각 평균 $6.60 \mathrm{~mm}, 7.23 \mathrm{~mm}$ 로 수술 후 측

Table 1. USG and CT measurements according to stone location

\begin{tabular}{|c|c|c|c|c|}
\hline \multirow{2}{*}{ Difference value } & \multicolumn{3}{|c|}{ Stone location } & \multirow{2}{*}{$F(p$-value $)$} \\
\hline & Anterior $(n=9)$, mean (SD) & Middle $(n=21)$, mean (SD) & Posterior $(n=50)$, mean (SD) & \\
\hline Post-OP vs. USG* (mm) & $0.444(1.667)$ & $1.095(2.119)$ & $1.52(1.940)$ & $1.282(0.283)$ \\
\hline Post-OP vs. $\mathrm{CT}^{\dagger}(\mathrm{mm})$ & $0.778(1.202)$ & $0.81(1.470)$ & $0.58(1.785)$ & $0.167(0.847)$ \\
\hline
\end{tabular}

* difference value between postoperative measurement and ultrasonographic measurement, tdifference value between postoperative measurement and computed tomographic measurement. OP: operation, USG: ultrasonography, CT: computed tomography

Table 2. USG and CT measurements according to presence of combined acute infection

\begin{tabular}{lccr}
\hline \multirow{2}{*}{ Difference value } & \multicolumn{2}{c}{ Acute infection } & $\dagger(p$-value $)$ \\
\cline { 2 - 3 } & No $(\mathrm{n}=67)$, mean $(\mathrm{SD})$ & Present $(\mathrm{n}=13)$, mean $(\mathrm{SD})$ & $0.882(0.381)$ \\
\hline Post-OP vs. USG* $(\mathrm{mm})$ & $1.373(2.014)$ & $0.846(1.725)$ & $-0.471(0.645)$ \\
Post-OP vs. $\mathrm{CT}^{\dagger}(\mathrm{mm})$ & $0.612(1.497)$ & $0.923(2.290)$ & \\
$\dagger(\mathrm{p}$-value $)$ & $4.912(0.000)$ & $-0.106(0.918)$ & \\
\hline
\end{tabular}

* difference value between postoperative measurement and ultrasonographic measurement, tdifference value between postoperative measurement and computed tomographic measurement. OP: operation, USG: ultrasonography, CT: computed tomography 
정값 평균 $7.89 \mathrm{~mm}$ 보다 통계적 유의성은 없지만 작은 값을 보였다. 이것은 영상학적 진단은 2차원 단면에서 최대 직경을 측정하므로 3 차원으로 존재하는 실제 타석의 최대 직경을 평 가함에 있어 한계가 있기 때문으로 판단된다. 따라서 초음파 또는 전산화단층촬영을 이용하여 타석의 크기를 평가할 경우 축면 뿐만 아니라 관상면 또는 시상면에서도 타석의 크기를 평가하고 가장 큰 값으로 타석의 크기를 평가하는 것이 보다 정확할 것으로 판단된다.

본 연구 결과에 의하면 실제 타석의 크기는 수술 전 예측값 보다 클 수 있으므로, 수술 전 영상검사를 통한 타석 크기를 기준으로 침샘 내시경 또는 충격파 돌깸술을 선택할 경우 주 의가 필요하다. 침샘 내시경과 충격파 돌깸술은 크기가 큰 타 석에서 그 유용성과 성공률에 제한이 있기 때문이다. 예를 들 면, 침샘 내시경 시행 중 실제 타석의 크기가 수술 전 예측보 다 큰 타석은 침샘관 내에서 타석의 운동성이 충분하지 않을 수 있으며, 이런 타석은 경구강 타석 제거술로 치료 방법의 전 환이 필요하게 된다. 그런데 타석의 운동성은 침샘 내시경 시 행 중에 평가 가능하므로, 수술 전 타석 크기의 정확한 평가 의 중요성이 강조된다고 하겠다.

본 연구에서 영상의학적 진단 시 타석의 크기 측정에 영향 을 줄 수 있는 인자를 고려하여 타석의 위치(앞쪽, 중간, 뒤쪽) 와 급성감염의 동반 유무에 따른 초음파 및 전산화단층촬영 을 이용한 악하선 타석의 크기 측정값의 차이를 분석하였지 만 유의한 차이점을 찾지 못하였다. 그런데, 급성감염이 있는 13 명에서는 초음파와 전산화단층촬영 두 검사가 차이가 없었 고, 급성감염이 없는 67 명에서는 전산화단층촬영이 초음파보다 악하선 타석을 정확히 예측하였다(Table 2). 급성 감염이 없는 67 명의 결과는 전체 대상자에서 전산화단층촬영의 상관계수 가 초음파의 상관계수보다 더 높은 것과 일치하는 소견이다.

결론적으로 본 연구에서 수술 전에 악하선 타석의 크기를 예측하는 데 있어 타석 위치와 감염 여부에 관계 없이 초음파 와 전산화단층촬영 모두 높은 정확도를 보였으며, 전산화단 층촬영이 초음파보다 좀 더 높은 정확도를 보였다. 하지만 실 제 타석은 수술 전 영상검사를 통한 예측보다는 크기가 클 수 있으므로, 타석의 크기를 기준으로 치료 방법을 선택할 때는 주의가 필요하다.

\section{REFERENCES}

1) Marchal F, Dulguerov P. Sialolithiasis management: the state of the art. Arch Otolaryngol Head Neck Surg 2003;129(9):951-6.

2) Park JS, Sohn JH, Kim JK. Factors influencing intraoral removal of submandibular calculi. Otolaryngol Head Neck Surg 2006;135(5): 704-9.

3) Kim JK, Park JS. Transoral removal of submandibular stone. Korean J Otolaryngol-Head Neck Surg 2006;49(1):60-5.

4) Witt RL, Iro H, Koch M, McGurk M, Nahlieli O, Zenk J. Minimally invasive options for salivary calculi. Laryngoscope 2012;122(6): 1306-11.

5) Marchal F, Dulguerov P, Lehmann W. Interventional sialendoscopy. N Engl J Med 1999;341(16):1242-3.

6) Zenk J, Koch M, Klintworth N, König B, Konz K, Gillespie MB, et al. Sialendoscopy in the diagnosis and treatment of sialolithiasis: a study on more than 1000 patients. Otolaryngol Head Neck Surg 2012; 147(5):858-63.

7) Capaccio P, Torretta S, Ottavian F, Sambataro G, Pignataro L. Modern management of obstructive salivary diseases. Acta Otorhinolaryngol Ital 2007;27(4):161-72.

8) Kopeć T, Wierzbicka M, Szyfter W, Leszczyńska M. Algorithm changes in treatment of submandibular gland sialolithiasis. Eur Arch Otorhinolaryngol 2013;270(7):2089-93.

9) Rzymska-Grala I, Stopa Z, Grala B, Gołębiowski M, Wanyura H, Zuchowska A, et al. Salivary gland calculi - contemporary methods of imaging. Pol J Radiol 2010;75(3):25-37.

10) Schwarz D, Kabbasch C, Scheer M, Mikolajczak S, Beutner D, Luers JC. Comparative analysis of sialendoscopy, sonography, and CBCT in the detection of sialolithiasis. Laryngoscope 2015;125(5):1098-101.

11) Vogl TJ, Al-Nawas B, Beutner D, Geisthoff U, Gutinas-Lichius O, Naujoks C, et al. Updated S2K AWMF guideline for the diagnosis and follow-up of obstructive sialadenitis--relevance for radiologic imaging. Rofo 2014;186(9):843-6.

12) Capaccio P, Ottaviani F, Manzo R, Schindler A, Cesana B. Extracorporeal lithotripsy for salivary calculi: a long-term clinical experience. Laryngoscope 2004;114(6):1069-73.

13) Escudier MP, Brown JE, Putcha V, Capaccio P, McGurk M. Factors influencing the outcome of extracorporeal shock wave lithotripsy in the management of salivary calculi. Laryngoscope 2010;120(8):1545-9.

14) Iro H, Zenk J, Escudier MP, Nahlieli O, Capaccio P, Katz P, et al. Outcome of minimally invasive management of salivary calculi in 4,691 patients. Laryngoscope 2009;119(2):263-8.

15) Nahlieli O, Nakar LH, Nazarian Y, Turner MD. Sialoendoscopy: a new approach to salivary gland obstructive pathology. J Am Dent Assoc 2006;137(10):1394-400.

16) Kim JK, Park JS. Ultrasound-guided transoral removal of impalpable hilar submandibular salivary stones. Laryngoscope 2007;117(8):1373-5.

17) Zhang L, Escudier M, Brown J, Capaccio P, Pignataro L, McGurk M. Long-term outcome after intraoral removal of large submandibular gland calculi. Laryngoscope 2010;120(5):964-6. 